\title{
Persistence of Antibiotic Residue in Milk under Region of Bihar, India
}

\author{
Ramesh Kumar Nirala*, Kumari Anjana, K.G. Mandal and C. Jayachandran \\ Department of Pharmacology and Toxicology, Bihar Veterinary College, Patna-800014, India \\ *Corresponding author
}

\section{A B S T R A C T}

Indiscriminate use of antimicrobial drugs posses a great threat to human population. Their residues in milk over a long time may produce a variety of manifestations like individual drug toxicities including drug allergies, carcinogenicity and most importantly microbial resistance to these drugs. Keeping in view of the above facts, monitoring of residues of enrofloxacin and its metabolites were done in North Bihar region. With the objectives to estimate the residues of these antibiotics in milk samples, sample survey was done in organized as well as unorganized dairy sectors. A total number of 250 milk samples consisting of 125 from organized and 125 from unorganized sectors were randomly collected out of which 50 sample from each districts of Bihar. The samples were stored in deep freeze till analysis. Samples were processed before high performance liquid chromatography (HPLC) analysis as per standard analytical procedures. Analytical methods for estimation of residues of tetracyclines, sulfonamides and fluoroquinolones were standardized. The antimicrobial residues in milk were estimated above MRL values [MRL values in respect of tetracyclines, sulfonamides and fluoroquinolones is $0.1 \mu \mathrm{g} / \mathrm{ml}$ ]. A total of five samples for tetracycline and two for oxytetracycline, two for sulfadimidine and one for sulfamethoxazole were found to contain residues above MRL values but no any sample of enrofloxacin and ciprofloxacin were found to concentration above MRL values i.e., $0.1 \mu \mathrm{g} / \mathrm{ml}$. On examination of history of individual animal samples, it was found that animals were given either recent treatment with these antibacterials without observing proper withdrawal periods. Other sources may be feed additive as growth promoters.

\section{Introduction}

Antibiotics residue in foods of animal origin are one of the sources of concern among the public and medical health professionals (Bren et al., 2002). Antimicrobial agents are widely used in milk producing animals for therapeutic and prophylactic purposes. Apart from this, they are also used as feed additives as growth promoters may result in presence of antimicrobial residues in milk and dairy products, and can contribute to the development of microbial drug resistance and the spread of resistant bacteria (Stolker et al., 2007). Also, the residues of Veterinary Medicinal Product i.e. antibiotics present a potential risk to the human population, particularly with the appearance of allergic reactions and interferences of intestinal micro-flora (Dewdeny et al., 1991). From the technological prospective, residues of antimicrobial agents in milk can cause significant losses in fermented products, by inhibition of bacterial fermentation in the 
production processes of cheese or yoghourt (Molina et al., 2003). Therefore, accurate detection of low levels of antimicrobial drug residues in milk is of great importance for the dairy industry and for farmers, with a purpose to ensure that the contaminated milk from individual cows is not consigned to the bulk tank (Mitchell et al., 2002). The fluoroquinolones antibiotics have wide range of antibacterial activity and have seen increasing use in veterinary medicine because of their effectiveness in treating bacterial infection (Cinquina et al., 2003). Enrofloxacin is a third generation fluoroquinolone exclusively used for veterinary practices against septicaemia, respiratory tract, urinary tract, soft tissues, bone and joint infection etc. (Sanjib et al., 2005). Enrofloxacin is a potent inhibitor of DNA-gyrase enzyme and is highly effective against many organisms that are resistant to $\beta$ lactamases, aminoglycosides, macrolides, tetracyclines, folic acid antagonist etc (Bauditz, 1987; Elmas et al., 2000) Consequently, it is necessary to monitor a large number of milk samples for the presence of the most important antimicrobial drug residues, for this highly sensitive analytical HPLC methods were used. Purpose and objective of this study have to detect antibiotics at or below their permissible limits or MRLs.

\section{Materials and Methods}

\section{Sampling}

A total of 250 raw milk samples were collected in January-April 2015 from organized and unorganized sectors from randomly selected five districts of Bihar out of which 50 sample from each districts of Bihar. The samples were stored at $-20{ }^{\circ} \mathrm{C}$ till analysis. Residual analysis of milk sample were performed by highly sensitive analytic chromatographic technique with Waters
HPLC System equipped with gradient pump 515 and dual UV detector 2487 as per standardized method

\section{Extraction of fluoroquinolones from milk}

Three ml of milk sample was mixed with 12 $\mathrm{ml}$ of $5 \%$ TCA. Mixed and vortexed for 2 minutes. Rotary agitation for 10 minutes was done. Centrifugation was done for 15 minutes at $4500 \mathrm{rpm}$. Supernatant was filtered on 0.45 $\mu \mathrm{m}$ nylon filter. $20 \mu \mathrm{l}$ was injected in the LC instrument.

\section{Preparation of standards}

Pure analytical standards of fluoroquinolones (Vetranal Analytical Standards obtained from Fluka, Sigma Aldrich) were used for the study. Pure standard of enrofloxacin was dissolved in $0.03 \mathrm{M} \mathrm{NaOH}$ and working standards of individual drugs in the range of $0.1-1000 \mathrm{ng} / \mathrm{ml}$ in water was prepared.

\section{Chromatographic conditions}

Waters HPLC System equipped with isocratic pump 515 and dual UV detector 2487 was used. Symmetry C18 column (4.5 mm x 250 $\mathrm{mm}$ with particle size of $5 \mu \mathrm{m})$ was used. UV detection was performed at $278 \mathrm{~nm}$. Mobile Phase consisted of Acetonitrile: Methanol: water $(17: 3: 80, \mathrm{v} / \mathrm{v} / \mathrm{v})$ and water containing $0.4 \%$ phosphoric acid $(85 \% \mathrm{v} / \mathrm{v}$ and $0.4 \%$ triethylamine v/v). Flow rate of $0.6 \mathrm{ml} / \mathrm{min}$ with loop size was $20 \mu \mathrm{l}$ and ambient column temperature was used.

\section{Results and Discussion}

The objective of this study was to monitor and analyze the residual level of Enrofloxacin and Ciprofloxacin in raw milk sample from five districts from north Bihar region, India 2015. A total 250 Samples collected from organized as well as unorganized dairy 
sectors were analyzed. Organized sector included organized dairy farms (both private and government) as well as local khatals. Unorganized sector included the marginal farmers who rear animals in few numbers but not in herds. The determined level of enrofloxacin residue in milk samples were then analyzed to compared the prevalent residue level with recommended maximum permissible residue limit to find whether the prevalent residue level are within the prescribed maximum limit in terms of consumers health protection. It was found that out of all the milk samples analyzed, eight samples $(3.2 \%)$ were found to contain antibiotics residue. Three samples (1.2 \%) exceeded the maximum residue levels (MRL) for enrofloxacin antibiotics according to the regulation set by the European Union and the Codex Alimentarious Comission.

Table.1 District wise samples analyzed and detected MRL values

\begin{tabular}{|l|l|l|l|l|l|}
\hline $\begin{array}{l}\text { Sl. } \\
\text { No }\end{array}$ & $\begin{array}{l}\text { Name of } \\
\text { Districts }\end{array}$ & $\begin{array}{l}\text { Total no. of } \\
\text { sample } \\
\text { analyzed }\end{array}$ & $\begin{array}{l}\text { Total no. of } \\
\text { sample Detected } \\
\text { Positive }\end{array}$ & $\begin{array}{l}\text { Maximum } \\
\text { residue }(\mu \mathrm{g} / \mathrm{kg})\end{array}$ & $\begin{array}{l}\text { No. of samples } \\
\text { found above } \\
\text { MRL }\end{array}$ \\
\hline 1 & Saran & 50 & 02 & 45.46 & Nil \\
\hline 2 & Siwan & 50 & 03 & 56.35 & Nil \\
\hline 3 & Gopalganj & 50 & 02 & 125.18 & 2 \\
\hline 4 & Muzaffarpur & 50 & Nil & Nil & Nil \\
\hline 5 & Motihari & 50 & 01 & 112.15 & 1 \\
\hline & Total & 250 & 08 & 125.18 & 3 \\
\hline
\end{tabular}

Fig.1 Calibration curve of enrofloxcin for residual anlaysis of enrofloxcain

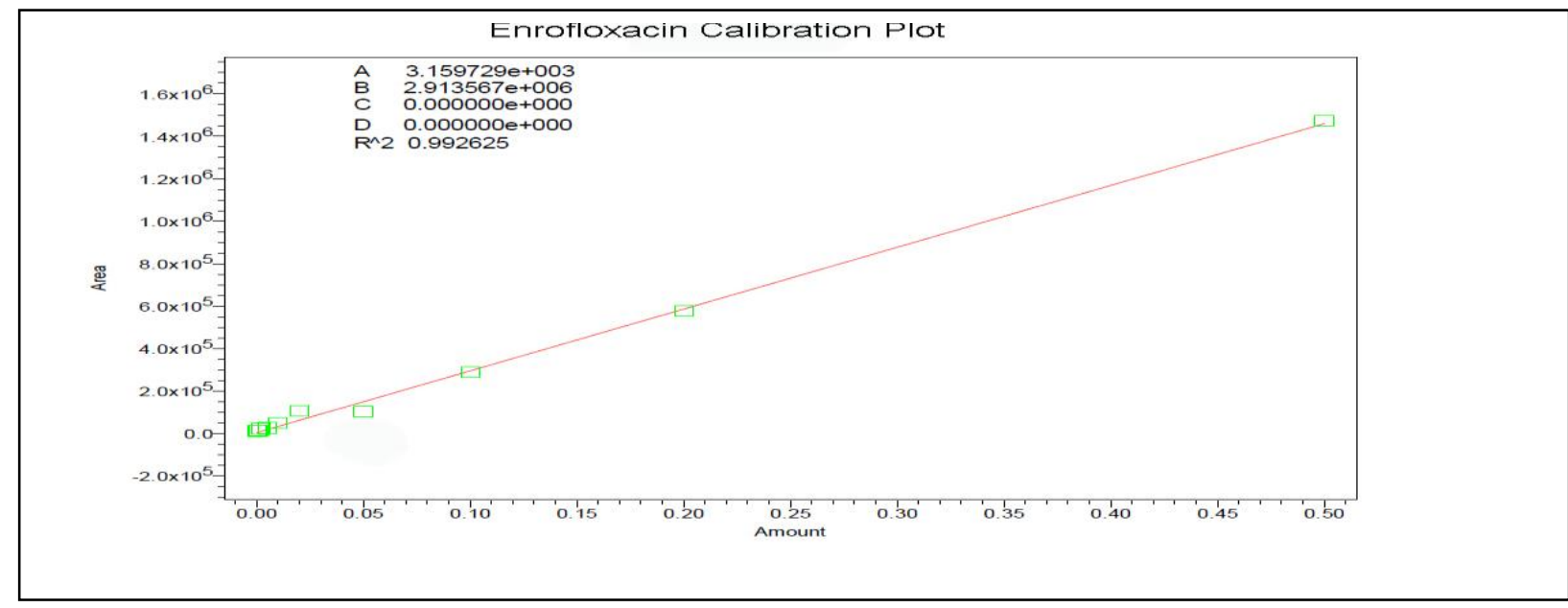

In conclusion residual monitoring of enrofloxacin in collected raw milk samples were done with HPLC analytical equipment with reliable methodology for antibiotic determination in milk on the basis these study we conclude that only three samples $(1.2 \%)$ were found to exceed the Maximum Residual Limit (MRL) which on further dilution after pooling will not be having any adverse effect on human health. It suggest that the present status of enrofloxacin contamination is within the specified limit but needs to be continuous 
monitoring to take timely remedial action to prevent its detrimental effects on public health.

\section{Acknowledgement}

The authors are thankful to Indian Council of Agricultural Research, New Delhi and Associate Dean-cum-Principal, Bihar Veterinary College, Patna-800014, Bihar State, India for providing funding along with necessary facilities to conduct the present study.

\section{References}

Bauditz, Bauditz, R. 1987. Results of clinical studies with Baytril TM. Poult. Vet. Med. Rev., 2: 130-136.

Bren, L. 2002. The Battle of the Bugs: Fighting Antibiotic Resistance. USDA Consumer Magazine 2002 Jul - Aug. http://www.fda.gov.fdac/features/2002/4 02_bugs.html., Accessed on 03-10-2013 Cinquina, A.L., et al. 2003. Determination of enrofloxacin and its metabolite ciprofloxacin in goat milk by highperformance liquid chromatography with diode-array detection Optimization and validation $J$. Chromatography. A 987: 221-226.

Dewdeny, J.M., Maes, L., Raynaud, J.P., Blanc, F., Scheid, J.P., Jackson, T., Lens, S., Verschueren, C. 1991. Risk assessment of antibiotic residues of beta-lactams and macrolides in foodproducts with regard to their immunoallergic potential, Food and Chem. Toxicol., 29: 477-483

Elmas, M., Yazar, E., Tras, B., Bas, A.L. and Eryavuz, A. 2000. Pharmacokinetics and oral Bioavailability of enrofloxacin in faunated and defaunated Angora goats. Revue Med. Vet., 6(151): 507510.

Mitchell, J.M., Groffi ths, M.W., Mcewen, S.A., McNab, W.B., Yee, A.J. 2002. Antimicrobial drug residues in milk and meat: Causes, concerns, prevalence, regulations, tests and test performance, J. Food Protection, 61: 742-756.

Molina, M.P., Althausb, R.L., Molinac, A., Fernándeza, N. 2003. Antimicrobial agent detection in ewe's milk by the microbial inhibitor test brilliant black reduction test - BRT AiM®, Int. Dairy J., 13: 821-826.

Sanjib, K., Chandana, C.B., Pritam, M. and Mohan, B. 2005. Pharmacokinetics stuies of enrofloxacin in Yak after intramuscular administration. Ir. J. Pharmacol. Therap., 4(2): 91-94

Stolker, A.A.M., Zuidema, T., Nielen, M.W.F. 2007. Residue analysis of veterinary drugs and growth-promoting agents. Trends in Anal. Chem., 26: 967979.

\section{How to cite this article:}

Ramesh Kumar Nirala, Kumari Anjana, K.G. Mandal and Jayachandran, C. 2017. Persistence of Antibiotic Residue in Milk under Region of Bihar, India. Int.J.Curr.Microbiol.App.Sci. 6(3): 2296-2299. doi: http://doi.org/10.20546/ijcmas.2017.603.262 